\title{
Penentuan Kadar Alkaloid Total pada Ekstrak Bunga Pepaya (Carica papaya L) dengan Metode Microwave Assisted Extraction
}

\author{
Iman Mukhaimin ${ }^{*}$, Anne Nur Latifahnya, Ernawati Puspitasari \\ Jurusan Teknik Kimia, Fakultas Teknik, Universitas Jenderal Achmad Yani \\ *email: mukhaiminiman056@gmail.com
}

Received: 22/10/2018; Revised: 22/11/2018; Accepted: 22/11/2018

\begin{abstract}
Abstrak
Bunga pepaya (Carica papaya L) mengandung senyawa bioaktif alkaloid seperti carpaine, pseudocarpaine dan dehydrocarpaine. Alkaloid tersebut dipercaya bermanfaat untuk sebagai obat antidengue, anticancer, antimicrobial, antiparasitic, anti-inflammatory, antioxidant, antidiabetic activities. Pada penelitian ini, bunga pepaya diekstrak menggunakan metode ekstraksi padat-cair menggunakan metode Microwave Assisted Extraction (MAE) dan ekstraksi cair-cair. Sebelum proses ekstraksi, bunga pepaya dikeringkan dan dikecilkan hingga memiliki ukuran partikel sebesar $0,125 \mathrm{~mm}$. Bunga pepaya yang telah kering diekstraksi menggunakan metanol $80 \%\left({ }^{\mathrm{v} /} \mathrm{v}\right.$ untuk menentukan pengaruh waktu ekstraksi (1-5 menit), daya microwave (40, 120, 200, 280 Watt), dan rasio sampel terhadap pelarut $\left(1: 10 ; 1: 15 ; 1: 20 \mathrm{~b} /{ }_{\mathrm{v}}{ }^{\mathrm{d}}\right.$ terhadap kadar alkaloid total. Hasil ekstrak menunjukkan hasil positif adanya alkaloid setelah diuji dengan pereaksi Mayer dengan terbentuknya endapan berwarna putih kekuningan. Adapun kadar alkaloid total terbesar adalah 0,02981 mg/g sampel dengan kondisi operasi ekstraksi waktu ekstraksi 3 menit, rasio sampel terhadap pelarut 1:10 $(\mathrm{m} / \mathrm{v})$ serta daya microwave 40 Watt.
\end{abstract}

Kata Kunci: Alkaloid total, Bunga Pepaya, Ekstraksi, Microwave Assisted Extraction

\begin{abstract}
Papaya flower (Carica papaya L) contain bioactive compound, alkaloid, such as carpaine, pseudocarpaine and dehydrocarpaine. alkaloid pepaya flower had been trusted could be a herb to cure antidengue, anticancer, antimicrobial, antiparasitic, anti-inflammatory, antioxidant, antidiabetic activities. Papaya flower was extracted with Microwave Assisted Extraction method and solvent extraction method. Before extraction process, papaya flower was dried and ground into 0.125 $\mathrm{mm}$ of particle size. Dried papaya flower was extracted with methanol $80 \%(\mathrm{v} / \mathrm{v})$ to determine influence of extraction time (1-5 minute), microwave power (40,120, 200, $200 \mathrm{Watt})$, and solid-liquid ratio $(1: 10 ; 1: 15 ; 1: 20 \mathrm{w} / \mathrm{v})$. As a result, Alkaloid was detected by formation deposit of yelowish white on phytochemical test with Mayer reagent . The highest Crude Alkaloid total is $0.02981 \mathrm{mg} / \mathrm{g} \mathrm{sample}$ on 3 minutes extraction time, 400 Watt microwave power, and solid-liquid ratio $1: 10(\mathrm{w} / \mathrm{v})$.
\end{abstract}

Keywords: Extraction, Microwave Assisted Extraction, Papaya flower, Total Alkaloid

\section{PENDAHULUAN}

Tanaman pepaya merupakan tanaman yang kaya akan manfaat. Setiap bagian dari tanaman pepaya memiliki manfaat tersendiri, mulai dari buah, batang, akar, bunga dan daun. Livestock Medicine menegaskan bahwa setidaknya ditemukan 22 jenis senyawa bioaktif. Hal ini membuat tanaman pepaya memiliki manfaat sebagai antidengue, anticancer, antimicrobial, 
antiparasitic, anti-inflammatory, antioxidant, antidiabetic activities (Annegowda \& Bhat, 2015), dan anti trombopenik (Zunjar et al., 2016). Daun pepaya mengandung vitamin A, C, B12, alkaloid carpaine, pseudocarpaine dan carposide sebesar $0,02-0,31 \%$ yang berfungsi sebagai anti malaria (Linn, n.d.). Kulit pepaya mengandung cyseteine protease, papain, chymopapain, dan caricain. Buah pepaya mengandung gula, asam fenolik, vitamin C. Biji pepaya mengandung alkaloid, flavanoid, triterpenoid, dan caricin (Annegowda \& Bhat, 2015). Kaya akan kandungan senyawa bioaktif tidak membuat semua bagian pepaya telah termanfaatkan dengan baik salah satunya adalah bunga pepaya.

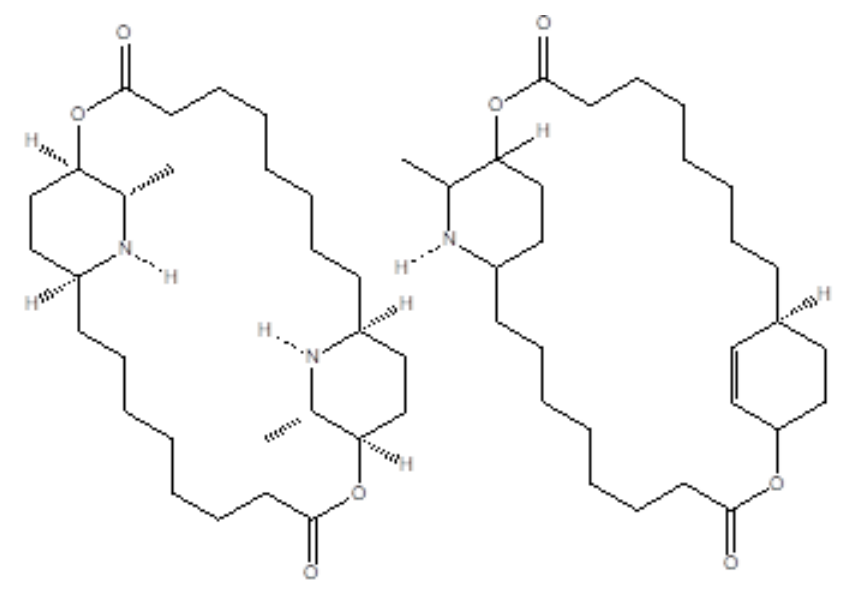

Carpaine dehydrocarpaine I flavonoid. Kandungan senyawa bioaktif di dalamnya membuat bunga pepaya bermanfaat sebagai obat penurun panas, penyakit kuning, asma (Vij \& Prashar, 2015) dan infeksi pernapasan (Baxter et al., 2008)

Salah satu yang paling khas dari senyawa aktif pada bunga pepaya adalah alkaloid. Alkaloid pada jaringan tanaman pepaya mayoritas tersimpan dalam bentuk basa bebasnya. Dimana kelarutan alkaloid bergantung pada struktur dari alkaloidnya sendiri (Murphy, 2016). Alkaloid karpain, pseudokarpain serta dehidrokarpain I dan II yang memiliki struktur seperti pada Gambar 1 memberikan ciri khas pada tanaman pepaya dengan rasa pahitnya (Julianti et al., 2014).
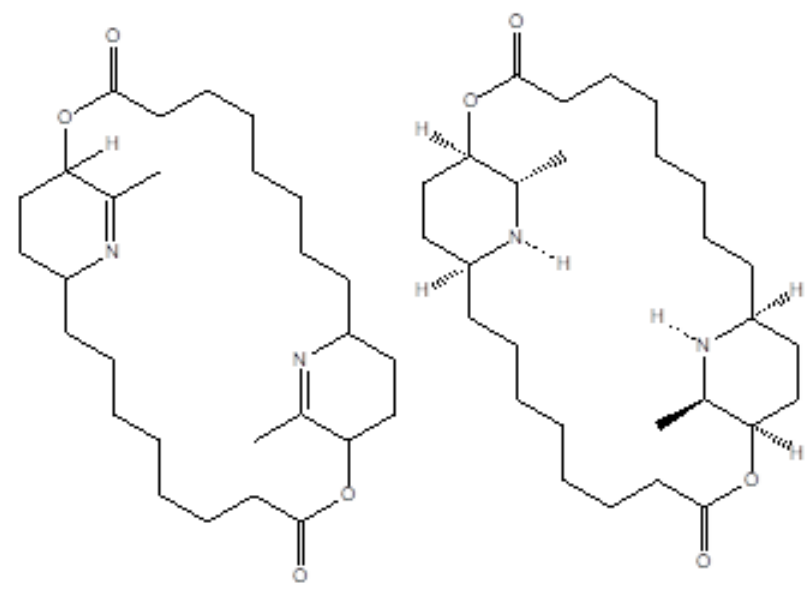

dehydrocarpaine II pseudocarpaine

Gambar 1. Struktur kimia senyawa alkaloid

Bunga pepaya terbagi menjadi tiga jenis, bunga jantan, betina dan hemaprodit. Presentase dari bunga menjadi buah yang hanya $27,6 \%$ membuat bunga pepaya yang tidak menjadi buah hanya digunakan sebagai tambahan bahan makanan, dan herba green tea (Bergonio \& Perez, 2016) sehingga ini menjadi menarik untuk dimanfaatkan. Penelitian Ukpabi et al. (2015) menyatakan bunga pepaya mengandung saponin, alkaloid, tanin dan
Senyawa alkaloid memiliki sifat farmakologi dan kegiatan fisiologis yang menonjol sehingga digunakan luas dalam bidang pengobatan (Widi \& Indriati, 2007). Berdasarkan pada pemanfaatannya yang besar, maka banyak dilakukan proses pengisolasian senyawa alkaloid dari berbagai tanaman, terutama tanaman dengan rasa pahit.

Penelitian berkaitan dengan pengisolasian senyawa alkaloid dari 
Penentuan Kadar Alkaloid Total pada Ekstrak Bunga Pepaya (Carica papaya L) dengan Metode Microwave Assisted Extraction

tanaman Carica papaya sudah pernah dilakukan dengan menggunakan metode ekstraksi maserasi (Rahman et al., 2015), Supercritical $\mathrm{CO}_{2}$ extraction (Barroso et al., 2016), metode soxhletasi (Ukpabi et al., 2015), dan metode refluks (Nugroho et al., 2017). Metode-metode tersebut telah berhasil mengisolasi senyawa alkaloid pada tanaman pepaya.

Namun masih membutuhkan waktu yang lama, jumlah pelarut yang besar, temperatur yang tinggi dan khusus metode superkritis membutuhkan proses yang lebih mahal karena dilakukan pada tekanan tinggi, sehingga perlu adanya metode ekstraksi lain yang digunakan untuk mengisolasi alkaloid yaitu dengan meggunakan metode Microwave-asisted Extraction (MAE).

Metode MAE, merupakan metode ekstraksi dengan mengguanakan bantuan gelombang mikro. Metode MAE banyak diterapkan oleh peneliti untuk mengekstrak alkaloid diantaranya seperti ekstraksi alkaloid pada Sthepanica sinicav (Xie et al., 2014), Crotalaria sessiliflora L (Tang et al., 2017). Pemilihan MAE dipilih karena memiliki kelebihan yaitu waktu ekstraksi relatif lebih singkat, lebih selektif serta jumlah rendemen yang relatif lebih banyak. (Michel \& Elfakir, 2013).

Adapun dalam penentuan kadar alkaloid total (Djilani et al., 2006) berhasil menggunakan metode pengendapan dengan reagen mayer sedangkan (Sreevidya \& Mehrotra, 2003) menggunakan metode pengendapan dengan reagen dragendoff. Oleh karena itu penelitian ini akan mengguanakan metode MAE untuk menentukan kadar alkaloid total bunga tanaman pepaya.

\section{METODE PENELITIAN}

\section{Bahan-Bahan}

Bunga pepaya dari petani lokal Cimahi, Jawa Barat, Indonesia, Metanol, Asam klorida, n-heksana, klorofom, amonium hidroksida (analitik grade) dibeli dari Brata. Co (Bandung,Indonesia), Pereksi Mayer dibeli dari Laboratorium Kimia UNJANI (Cimahi, Indonesia)

\section{Preparasi Sampel}

Bunga pepaya segar dicuci dan dibersihkan dari tanah, debu dan kotoran lainnya. Bunga pepaya dikeringkan dibawah sinar matahari dan di oven (mammert) pada temperatur $50^{\circ} \mathrm{C}$ selama 24 jam. Bunga pepaya dikecilkan ukurannya untuk memperbesar luas permukaan partikel hingga memiliki ukuran lolos 60 mesh $(0,125 \mathrm{~mm}) .10$ gram bubuk bunga pepaya kering disimpan dalam plastik sampel pada temperatur ruang untuk digunakan pada proses ekstraksi.

\section{Microwave-assisted Extraction (MAE)}

Proses ekstraksi menggunakan microwave (Sharp R-230RS) yang telah dimodifikasi dengan daya 40-400 Watt dan frekuensi $2450 \mathrm{MHz}$. Ekstraksi berlangsung pada sistem tertutup dengan kondensor ulir, labu ekstraksi $250 \mathrm{~mL}$, dan magnetik stirer seperti pada Gambar 2. Bunga pepaya kering diekstraksi menggunakan pelarut metanol $80 \% \mathrm{v} / \mathrm{v}$ dengan variabel rasio sampel terhadap pelarut $(1: 10,1: 15,1: 20$ $\mathrm{b} / \mathrm{v}$ ), daya microwave (40, 120, 200, 280 Watt), dan (Waktu ekstraksi (1-5 menit).

\section{Uji Fitokimia}

Uji fitokimia alkaloid dilakukan seperti percobaan Jha et al., (2012), Ekstrak disaring, kemudian $10 \mathrm{~mL}$ filtrat ekstrak ditambahkan $\mathrm{HCl} 2 \%$ sampai $\mathrm{pH}$ 2-3, kemudian ditambahkan $15 \mathrm{~mL}$ pereaksi 
Penentuan Kadar Alkaloid Total pada Ekstrak Bunga Pepaya (Carica papaya L) dengan Metode Microwave Assisted Extraction

Mayer. Endapan berwarna putih kekuningan yang mengindikasikan bahwa ekstrak positif mengandung senyawa alkaloid.

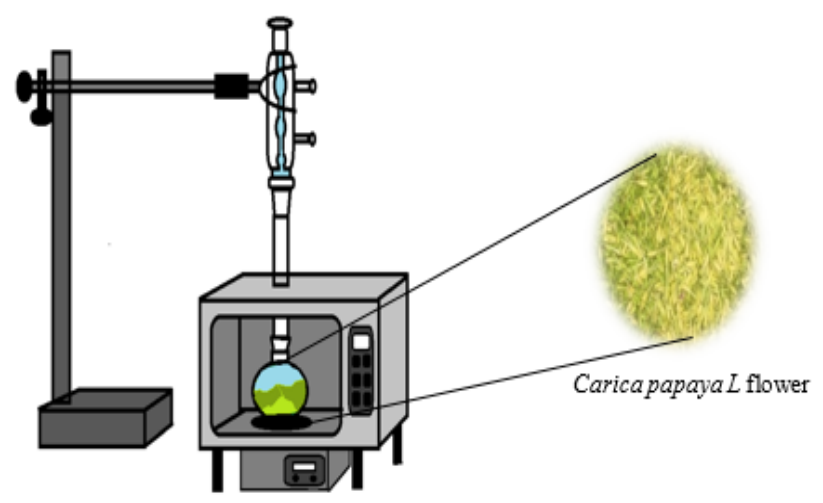

Gambar 2. Rangkaian alat Microwave Assisted Extraction

\section{Penentuan Kadar Alkaloid Total}

Penentuan crude alkaloid total dilakukan dengan metode ekstraksi cair-cair seperti metode Djilani et al., (2006). Ekstrak bunga pepaya yang telah disaring dipekatkan dengan hotplate disertai pengadukan konstan pada temperatur $50^{\circ} \mathrm{C}$. Ekstrak pekat ditambahkan $25 \mathrm{~mL} \mathrm{HCl} 2 \%$ dan $25 \mathrm{~mL}$ n-heksana. Kemudian diekstraksi dalam corong pisah $250 \mathrm{~mL}$ (Pyrex). Ekstrak asam klorida ditambahkan amonium hidroksida $35 \%$ b $/ \mathrm{b}$ sampai $\mathrm{pH} 9$, ditambah $25 \mathrm{~mL}$ klorofom dan diekstrak dalam corong pisah $250 \mathrm{~mL}$ (Pyrex). Pemberian klorofom dilakukan dua kali dan diuapkan sampai didapat padatan crude alkaloid total bunga pepaya.

\section{HASIL DAN PEMBAHASAN}

\section{Uji Fitokimia}

Uji fitokimia dilakukan untuk mengetahui kandungan senyawa alkaloid dalam ekstrak bunga Carica papaya dengan menggunakan pereaksi Mayer. Berdasarkan hasil penelitian yang didapatkan, warna larutan pereaksi Mayer yang pada awalnya bening (tidak berwarna) setelah direaksikan dengan ekstrak alkaloid menimbulkan endapan berwarna putih kekuningan seperti pada Gambar 3. Hal ini serupa dengan hasil penelitian Jha et al., (2012) bahwa endapan putih kekuningan tersebut merupakan endapan kalium-merkuri-iodida-alkaloid yang mengindikasikan bahwa ekstrak positif mengandung senyawa alkaloid.

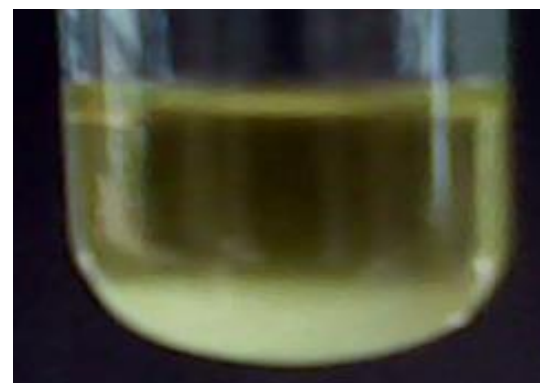

Gambar 3. Hasil Uji fitokimia alkaloid ekstrak bunga pepaya

\section{Pengaruh Waktu Ekstraksi terhadap Perolehan Kadar Senyawa Alkaloid Total}

Penentuan pengaruh waktu ekstraksi terhadap perolehan kadar senyawa alkaloid total dilakukan dengan rasio sampel-pelarut 1:10 (b/v) dan daya microwave 40 Watt. Gambar 4 menunjukkan peningkatan waktu ekstraksi akan meningkatkan temperatur ekstraksi. Peningkatan waktu ekstraksi akan memberi kesempatan kepada metanol untuk menyerap gelombang microwave lebih lama sehingga kalor yang dihasilkan dari proses rotasi dipol dan konduksi ion pada pelarut akan semakin meningkatkan temperatur ekstraksi. Hal ini yang menyebabkan temperatur ekstraksi terus mengalami peningkatan dimulai $29^{\circ} \mathrm{C}$ pada menit pertama sampai dengan $50^{\circ} \mathrm{C}$ pada menit kelima.

Hal ini tentu selaras dengan yang dikemukakan oleh Elwin (2014), bahwa peningkatan temperatur ekstraksi berhubungan dengan faktor disipasi metanol yaitu 0,659 sehingga waktu 
ekstraksi yang semakin lama akan menyebabkan pengkonversian energi elektromagnetik menjadi energi panas. Selain itu, peningkatan temperatur ekstraksi akan membantu mempercepat proses ekstraksi dengan merusak jaringan dinding sel pada bunga pepaya sehingga ekstrak alkaloid dapat terekstrak dengan cepat.

Hal ini sesuai dengan data pada Gambar 4 yang menunjukkan bahwa adanya peningkatan kadar alkaloid total dari menit ke-1 (0,015 mg/g) ,ke-2 (0,026 $\mathrm{mg} / \mathrm{g})$ dan menit ke-3 (0,030 mg/g). Perolehan pada menit ke-3 ini lebih tinggi dari hasil penelitian Ukpabi et al. (2015) yaitu $0,05 \pm 0,011 \%$ dengan metode sokletasi. Namun, pada menit ke-4 dan ke5, kadar alkaloid total menurun menjadi 0,028 dan $0,02 \mathrm{mg} / \mathrm{g}$. Penurunan ini dikarenakan temperatur ekstraksi menit ke$4\left(40^{\circ} \mathrm{C}\right)$ dan ke-5 $\left(50^{\circ} \mathrm{C}\right)$ melewati suhu degradasinya.

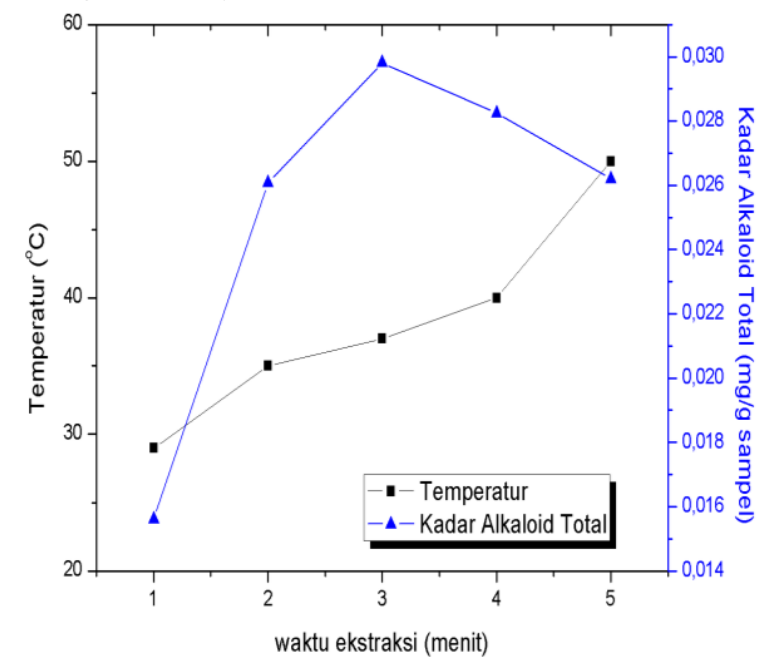

Gambar 4. Pengaruh waktu ekstraksi terhadap temperatur ekstraksi dan yield alkaloid total.

Julianti et al. (2014) dengan metode soxhlet menyatakan bahwa temperatur degradasi ekstraksi alkaloid pepaya pada temperatur $90^{\circ} \mathrm{C}$ dengan perolehan $0,31 \%$ (0,31 $\mathrm{mg} / \mathrm{g}$ daun pepaya). Temperatur degradasi alkaloid yang berbeda antara metode sokletasi dan MAE dikarenakan pada proses pemanasan langsung pada MAE, pemanasan akan kontak langsung dengan matriks sampel dengan lebih cepat sehingga dengan temperatur yang lebih rendah pada metode MAE dapat merusak senyawa alkaloid pada ekstrak bunga pepaya.

\section{Pengaruh Daya Microwave Terhadap Perolehan Kadar Alkaloid Total}

Pengaruh daya microwave dilakukan dengan rasio sampel : pelarut 1:10 (b/v), waktu ekstraksi 3 menit dan daya microwave 40-280 Watt. Pengaturan daya pada pengoperasian MAE berhubungan dengan energi dan temperatur ekstraksi. Gambar 5 menunjukkan bahwa peningkatan daya microwave meningkatkan temperatur ekstraksi dimulai pada daya 40 Watt dengan temperatur $37^{\circ} \mathrm{C}$ sampai dengan daya 280 Watt yang mencapai temperatur $70^{\circ} \mathrm{C}$. Peningkatan temperatur ini sesuai dengan pendekatan prediksi Absorbed Power Density (APD) dan Absorbed Energy Density (AED) yang dikemukakan oleh (Chan et al., 2014) bahwa total energi microwave yang diserap akan berbanding lurus dengan waktu ekstraksi dan daya dari microwavenya.

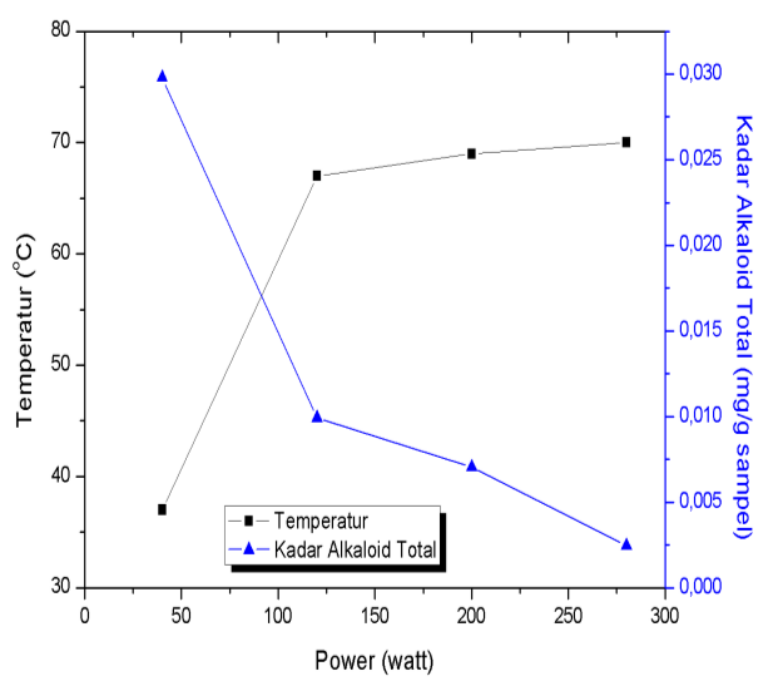

Gambar 5. Pengaruh daya microwave terhadap temperatur ekstraksi dan yield alkaloid total 
Penentuan Kadar Alkaloid Total pada Ekstrak Bunga Pepaya (Carica papaya L) dengan Metode Microwave Assisted Extraction

Namun, peningkatan temperatur mengakibatkan menurunnya kadar total alkaloid dari $0,02981 \mathrm{mg} / \mathrm{g}$ pada 40 watt sampai dengan $0,00246 \mathrm{mg} / \mathrm{g}$ pada 280 Watt. Hal ini dikarenakan temperatur ekstraksi, $67^{\circ} \mathrm{C}$, pada 120 Watt melebihi temperatur degradasi dari alkaloid bunga pepaya. Hasil ini tentu sesuai dengan hasil pada Gambar 4 yang menyatakan penurunan kadar total alkaloid ketika temperature ekstraksi melebihi $37^{\circ} \mathrm{C}$.

\section{Pengaruh Rasio S/L Terhadap Perolehan Kadar Alkaloid Total}

Untuk mengetahui pengaruh rasio $\mathrm{S} / \mathrm{L}$ $(1: 10 ; 1: 15 ; 1: 20 \mathrm{~b} / \mathrm{v})$ terhadap perolehan kadar senyawa alkaloid total dilakukan ekstraksi dengan waktu ekstraksi 3 menit dan daya 40 Watt seperti pada Gambar 6. Pada proses ekstraksi, penggunaan komposisi sampel dan pelarut yang tepat dapat memaksimalkan perolehan senyawa target. Umumnya dalam teknik ekstraksi konvensional volume pelarut lebih tinggi akan meningkatkan perolehan senyawa target, tetapi dalam MAE volume pelarut lebih tinggi dapat memberikan perolehan yang lebih rendah (Maran \& Prakash, 2015).

Hal ini dikarenakan proses pemanasan langsung pada MAE dengan volume yang lebih besar membuat pelarut memiliki kemampuan yang lebih untuk menyerap gelombang mikro dan mengkonversinya menjadi energi panas. Namun pada penelitian ini berdasarkan data di Gambar 6 tidak terjadi demikian, karena dengan adanya pelarut yang berlebih dapat mengakibatkan terjadinya excessive swelling pada bahan yang akan menimbulkan thermal stress berlebih sehingga timbulnya panas yang cepat pada larutan akibat dari penyerapan gelombang mikro oleh pelarut. Thermal stress yang berlebih akan berakibat negatif terhadap senyawa-senyawa (Xie et al., 2014).

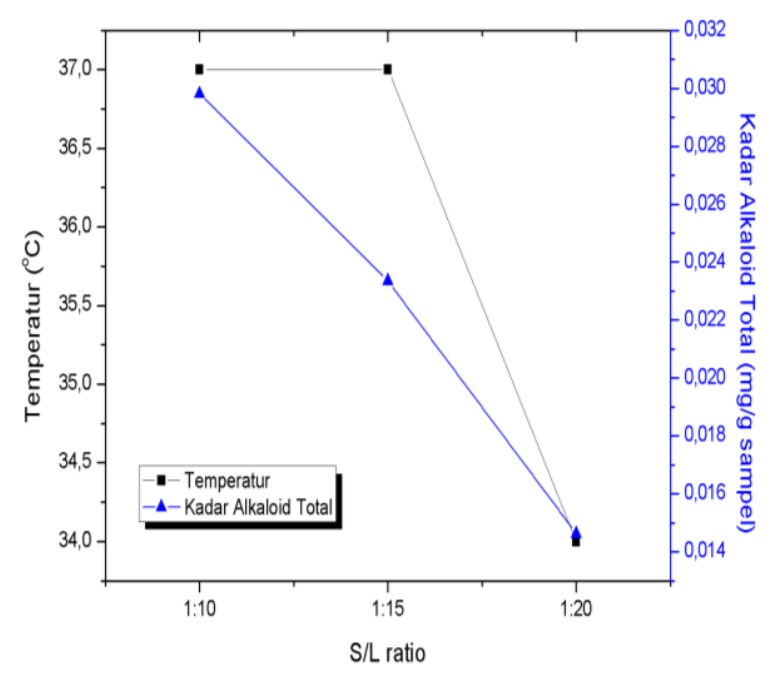

Gambar 6. Pengaruh Rasio S/L terhadap Perolehan Kadar Senyawa Alkaloid Total

Selain itu, rasio S/L yang tepat dapat memberikan kesetimbangan antara sampeldan pelarut sehingga proses ekstraksi dapat berlangsung secara optimum. Perolehan kadar alkaloid total terbaik adalah pada rasio S/L 1:10 sebesar $0,02981 \mathrm{mg} / \mathrm{g}$ dengan temperatur ekstraksi $37^{\circ} \mathrm{C}$.

\section{KESIMPULAN}

Peningkatan daya microwave dan waktu ekstraksi akan meningkatkan temperatur ekstraksi. Sedangkan peningkatan rasio S/L akan mengakibatkan penurunan perolehan kadar alkaloid total. Perolehan kadar alkaloid terbaik terjadi pada rasio $\mathrm{S} / \mathrm{L}$ 1:10 $(\mathrm{m} / \mathrm{v})$, daya microwave 40 Watt, waktu ekstraksi 3 menit pada temperatur $37^{\circ} \mathrm{C}$ dengan kadar senyawa alkaloid total sebesar $0,02981 \mathrm{mg} / \mathrm{g}$.

\section{UCAPAN TERIMA KASIH}

Terima kasih Kepada LPPM UNJANI atas dukungan dana pada penelitian ini 
Penentuan Kadar Alkaloid Total pada Ekstrak Bunga Pepaya (Carica papaya L) dengan Metode Microwave Assisted Extraction

\section{DAFTAR RUJUKAN}

Annegowda, H. V., \& Bhat, R. (2015). Composition of Pepaya Fruit and Pepaya Cultivars. Nutritional Composition of Fruit Cultivars. Elsevier Inc. https://doi.org/10.1016/B978-0-12408117-8.00021-0

Barroso, P. T. W., de Carvalho, P. P., Rocha, T. B., Pessoa, F. L. P., Azevedo, D. A., \& Mendes, M. F. (2016). Evaluation of the composition of Carica papaya L. seed oil extracted with supercritical $\mathrm{CO}$. Biotechnology Reports, 11, 110-116. https://doi.org/10.1016/j.btre.2016.08.00 4

Baxter, R., Hastings, N., Law, a., \& Glass, E. J. (2008). [ No Title ]. Animal Genetics, $39(5), 561-563$.

Bergonio, K. B., \& Perez, M. A. (2016). The potential of male pepaya (Carica papaya, L.) flower as a functional ingredient for herbal tea production. Indian Journal of Traditional Knowledge, 15(1), 41-49.

Chan, C. H., Yusoff, R., \& Ngoh, G. C. (2014). Optimization of microwave-assisted extraction based on absorbed microwave power and energy. Chemical Engineering Science, 111, 41-47. https://doi.org/10.1016/j.ces.2014.02.011

Djilani, A., Legseir, B., Soulimani, R., Dicko, A., \& Younos, C. (2006). New extraction technique for alkaloids. Journal of the Brazilian Chemical Society, 17(3), 518520. https://doi.org/10.1590/S010350532006000300013

Elwin. (2014). Analisa Pengaruh Waktu Pretreatment Dan Konsentrasi Naoh Terhadap Kandungan Selulosa, Lignin dan Hemiselulosa Eceng Gondok Pada Proses Pretreatment Pembuatan Bioetanol. Universitas Brawijaya. Malang

Jha, D. K., Panda, L., \& Lavanya, P. (2012). Detection and Confirmation of Alkaloids in Leaves of Justicia adhatoda and Bioinformatics Approach to Elicit Its Anti-tuberculosis Activity. Appl Biochem
Biotechnol, $\quad$ s7-V(120), 287. https://doi.org/10.1007/s12010-0129834-1

Julianti, T., Oufir, M., \& Hamburger, M. (2014). Quantification of The Antiplasmodial Alkaloid Carpaine in Papaya (Carica papaya) Leaves. Planta Med.Vol. 80, 1138-1142.

Linn, C. (n.d.). Paw Paw, 1-5.

Maran, J., \& Prakash, K. (2015). Process Variables Influence on Microwave Assisted Extraction of Pectin from Waste Carica papaya L. peel. International Journal of Biological Macromolecules, 202-206.

Michel, T., \& Elfakir, C. (2013). MicrowaveAssisted Extraction. RSC Green Chemistry, 113-151.

Murphy, D. J. (2016). Alkaloids. Encyclopedia of Applied Plant Sciences (Vol. 2). Elsevier Inc. https://doi.org/10.1016/B978-0-12394807-6.00221-5

Nugroho, A., Heryani, H., Choi, J. S., \& Park, H. J. (2017). Identification and quantification of flavonoids in Carica papaya leaf and peroxynitrite-scavenging activity. Asian Pacific Journal of Tropical Biomedicine, 7(3), 208-213. https://doi.org/10.1016/j.apjtb.2016.12.00 9

Rahman, G. M., Wardatun, S., \& Wiendarlina, I. Y. (2015). Isolasi dan Karakterisasi Alkaloid Total Daun Pepaya Gandul (Carica papaya L.). Jurnal Penelitian Vol.1, 1-6.

Sreevidya, N., \& Mehrotra, S. (2003). Spectrophotometric method for estimation of Alkaloids precipitable with dragendorff's reagent in plant materials. Journal of AOAC International, 86(6), 1124-1127.

Tang, X., Zhu, D., Huai, W., Zhang, W., Fu, C., Xie, X., ... Fan, H. (2017). Simultaneous extraction and separation of flavonoids 
and alkaloids from Crotalaria sessiliflora L. by microwave-assisted cloud-point extraction. Separation and Purification Technology, 175, 266-273. https://doi.org/10.1016/j.seppur.2016.11. 038

Ukpabi, S. C., Emmanuel, O., \& Ezikpe, C. (2015). Chemical Composition of Carica Papaya Flower (Paw-Paw). International Journal of Scientific Research and Engineering Studies (IJSRES) Volume 2 Issue 3, 55-57.

Vij, T., \& Prashar, Y. (2015). A review on medicinal properties of Carica papaya Linn. Asian Pacific Journal of Tropical Disease, 5(1), 1-6. https://doi.org/10.1016/S22221808(14)60617-4

Widi, R. K., \& Indriati, T. (2007). Penjaringan dan Identifikasi Senyawa Alkaloid dalam Batang Kayu Kuning (Arcangelisia Flava Merr) . Jurnal ILMU DASAR, Vol. 8 No. 1, 24-29.

Xie, D. T., Wang, Y. Q., Kang, Y., Hu, Q. F., $\mathrm{Su}, \mathrm{N}$. Y., Huang, J. M., ... Guo, J. X. (2014). Microwave-assisted extraction of bioactive alkaloids from Stephania sinica. Separation and Purification Technology, 130 , 173-181. https://doi.org/10.1016/j.seppur.2014.04. 026

Zunjar, V., Dash, R. P., Jivrajani, M., Trivedi, B., \& Nivsarkar, M. (2016). Antithrombocytopenic activity of carpaine and alkaloidal extract of Carica papaya Linn. leaves in busulfan induced thrombocytopenic Wistar rats. Journal of Ethnopharmacology, 181, 20-25. https://doi.org/10.1016/j.jep.2016.01.035 